\title{
Realization of Streamline Visualization Based on MATLAB and CFD Database
}

\author{
Yirui Yang \\ School of Electrical Engineering, North China Electric Power University, 071000, China
}

\begin{abstract}
The CFD numerical calculation result visualization is an important part of the numerical simulation. Streamline visualization is an important technique for flow field visualization. Matlab is a widely used development tool with powerful graphics capabilities. It is very easy to realize the visualization of calculation result with Matlab. The method to access database and the method to draw streamline with MATLAB were elaborated. The streamline visualization program based on CFD database was developed with MATLAB. The streamline of backward facing step flow is drawn based on the numerical calculation result with the developed streamline visualization program. The location conditions of flow field in the protract example are accurately shown.
\end{abstract}

KEYWORD: MATLAB; visualization; streamlines; CFD; Database

\section{INTRODUCTION}

Along with the rapid development of the computer technology, computational fluid dynamics, computational heat transfer and computational combustion theory, high-grade microcomputer has been to use for numerical calculation of large power equipment. Realizing the flow field visualization in the power equipment according to the results of numerical calculation is an important means to improve the structure and the performance of power equipment. Streamline visualization is one of the methods of flow field visualization and plays an important role in understanding the complex fluid mechanism. Streamline visualization involved in the knowledge of computer graphics, computer image processing, computer aided design and computer programming, it is not easy to implement. Buying related software products from the market can realize streamline visualization, but these software targeted for CFD (Computational Fluid Dynamics) is very few, and it's expensive. Therefore, in this case, selfdevelopment may be a way which is worth considering. The main difficulty of self-development is that it is not easy to be familiar with and master the knowledge and technology of related disciplines and fields. Therefore, in order to achieve this goal, a suitable development tools will play an important role.

MATLAB combines scientific computing, data visualization and program design. It not only can meet users' demand for science and mathematics, and has strong ability of data visualization. We can achieve data visualization easily by using MATLAB. ACCESS is a software issued by Microsoft Company based on Windows desktop Relational Database Management System. It widely supports a variety of data types, has high data sharing and low low redundancy, and it's easy to use and expand. MATLAB can easily access Access/Jet, Microsoft SQL Server, Oracle (Oracle software company) or any ODBC compliant database data.

Based on the above consideration, this article will house CFD data in ACCESS2003 database, choose MATLAB2013a as CFD streamline visualization programming language.

\section{STREAMLINE DATABASE AND SQL COMMANDS}

The entire supermarket shopping guide system is mainly composed of supermarket coordinate, shopping cart and server.The computation areas is parted into four overlapping discrete girds: G, Gx, Gy and Gxy. Grid G is a grid that is divided by cell centered scheme. Grid Gx is a grid shifted by half control volume on the $\mathrm{X}$ axis based on the $\mathrm{G}$ grid. Grid Gy is a grid shifted by half control volume on the $\mathrm{Y}$ axis based on the G grid. Grid Gxy is a grid shifted by 
half control volume on both the $\mathrm{X}$ and $\mathrm{Y}$ axis based on the $\mathrm{G}$ grid.

The name of CFD computation database is FlowField.mdb, where the only two tables, $\mathrm{U}$ and $\mathrm{V}$ are related to the streamline. The structure of the Table $\mathrm{U}$ and $\mathrm{V}$ is listed in the following table:

Tab.1 Speed Table U

\begin{tabular}{|c|c|c|c|c|c|c|}
\hline \multirow[b]{2}{*}{$\begin{array}{l}\text { Field } \\
\text { Name }\end{array}$} & \multirow[b]{2}{*}{$\begin{array}{l}\text { Data } \\
\text { Type }\end{array}$} & \multicolumn{5}{|c|}{ Field Properties } \\
\hline & & $\begin{array}{l}\text { Field } \\
\text { Size }\end{array}$ & Mandatory & $\begin{array}{l}\text { Allow } \\
\text { Null }\end{array}$ & Index & $\begin{array}{l}\text { Primary } \\
\text { Key }\end{array}$ \\
\hline ID & Long & & $\mathrm{Y}$ & $\mathrm{N}$ & $\mathrm{Y}$ & $\mathrm{Y}$ \\
\hline I & Long & & $\mathrm{Y}$ & $\mathrm{N}$ & $\mathrm{N}$ & $\mathrm{N}$ \\
\hline $\mathrm{J}$ & Long & & $\mathrm{Y}$ & $\mathrm{N}$ & $\mathrm{N}$ & $\mathrm{N}$ \\
\hline $\mathrm{U}$ & Double & & $\mathrm{Y}$ & $\mathrm{N}$ & $\mathrm{N}$ & $\mathrm{N}$ \\
\hline UX & Double & & $\mathrm{Y}$ & $\mathrm{N}$ & $\mathrm{N}$ & $\mathrm{N}$ \\
\hline$\overline{U Y}$ & Double & & $\mathrm{Y}$ & $\mathrm{N}$ & $\mathrm{N}$ & $\mathrm{N}$ \\
\hline UXY & Double & & $\mathrm{Y}$ & $\mathrm{N}$ & $\mathrm{N}$ & $\mathrm{N}$ \\
\hline
\end{tabular}

Tab. 2 Speed Table V

\begin{tabular}{|c|c|c|c|c|c|c|}
\hline \multirow{2}{*}{$\begin{array}{l}\text { Field } \\
\text { Name }\end{array}$} & \multirow{2}{*}{$\begin{array}{l}\text { Data } \\
\text { Type }\end{array}$} & \multicolumn{5}{|c|}{ Field Properties } \\
\hline & & $\begin{array}{l}\text { Field } \\
\text { Size }\end{array}$ & Mandatory & $\begin{array}{l}\text { Allow } \\
\text { Null }\end{array}$ & Index & $\begin{array}{l}\text { Primary } \\
\text { Key }\end{array}$ \\
\hline ID & Long & & $\mathrm{Y}$ & $\mathrm{N}$ & Y & $\mathrm{Y}$ \\
\hline I & Long & & $\mathrm{Y}$ & $\mathrm{N}$ & $\mathrm{N}$ & $\mathrm{N}$ \\
\hline $\mathrm{J}$ & Long & & $\mathrm{Y}$ & $\mathrm{N}$ & $\mathrm{N}$ & $\mathrm{N}$ \\
\hline $\mathrm{V}$ & Double & & $\mathrm{Y}$ & $\mathrm{N}$ & $\mathrm{N}$ & $\mathrm{N}$ \\
\hline $\mathrm{VX}$ & Double & & $\mathrm{Y}$ & $\mathrm{N}$ & $\mathrm{N}$ & $\mathrm{N}$ \\
\hline VY & Double & & $\mathrm{Y}$ & $\mathrm{N}$ & $\mathrm{N}$ & $\mathrm{N}$ \\
\hline VXY & Double & & $\mathrm{Y}$ & $\mathrm{N}$ & $\mathrm{N}$ & $\mathrm{N}$ \\
\hline
\end{tabular}

ID is the record ID, I is the ID of the Grid at X axis, $\mathrm{J}$ is the ID of the Grid at Y axis, $\mathrm{U}$ is the velocity of the Grid $G$ at $X$ axis, $U X$ is the velocity of the Grid Gx at $\mathrm{X}$ axis, $\mathrm{UY}$ is the velocity of the Grid Gy at $\mathrm{X}$ axis, UXY is the velocity of the Grid Gxy at $\mathrm{X}$ axis, $\mathrm{V}$ is the velocity of the Grid $\mathrm{G}$ at $\mathrm{Y}$ axis, $\mathrm{VX}$ is the velocity of the Grid Gx at Y axis, VY is the velocity of the Grid Gy at Y axis, VXY is the velocity of the Grid Gxy at Y axis.

A streamline SQL is created to prepare the data to draw the streamlines in the CFD database. The SQL commands are shown as follows:

SELECT U.J AS J, U.I AS I, U.UXY AS UXY, V.VXY AS VXY FROM U, V

WHERE ((U.I=V.I)) And ((U.J=V.J)) and (U.I $>=1$ And $\mathrm{U} . \mathrm{I}<=350)$ And $(\mathrm{U} . \mathrm{J}>=1$ And $\mathrm{U} . \mathrm{J}<=100)$

ORDER BY U.J, U.I

\section{MATLAB DATABASE ACCESS}

Currently there are three commonly methods used API for database access: ODBC (Open Database Connectivity), JDBC and OLE-DB[2]. ODBC is selected in this paper as the API. In the paper, ODBC is used to access database.

\subsection{Data Source Configuration}

Data source shall be configured for database access when using ODBC. The basic steps for the data source configuration are list below:

(1) Choose Administrative Tools icon from Windows Control Panel, then choose the Data Sources shortcut, or run "odbbc32.ext" command directly. The ODBC data source stores the specified data provider connection information.

(2) The data source is listed in the the user DNS panel.

(3) In the ODBC Data Source Administrator dialog box, click Add, then select the data provider from the Installed ODBC Drivers list and choose OK. In the popup window, we choose Driver Do Microsoft Access(*.mdb) as the ODBC driver, and FlowField.mdb as the database. The data source is FlowField.

\subsection{Database Connection}

Connect to the database with the MATLAB database function, using the datasourcename, username and password.

conn=database('datasourcename', 'username', 'password')

conn is returned as a database handle, which can be used to access the database.

Where datasourcename is the datasource name, username is the user name, password is the database password.

\subsection{Database Query}

To access the database, you need to get the cursor. cursor $=$ exec(conn,'sqlquery')

The EXEC function returns a cursor object. Then use the FETCH function to import data from the cursor.

cursor $=$ fetch(cursor, RowLimit)

The RowLimit in the function is an option, which defines the maximum row number to import.

Data $=$ cursor.Data

The imported data is saved in the Data field of the cursor object, which can be assigned to another variable.

\section{STREAMLINE VISUALIZATION WITH MATLAB}

MATLAB has built-in plotting and charting functions which can be utilized to visualize the streamlines. The 2-dimentional streamline function has the following format:

streamline $(\mathrm{X}, \mathrm{Y}, \mathrm{U}, \mathrm{V}$,startX,startY)

This function can be used to plot the streamline of the 2-dimensional velocity vector field. $\mathrm{U}$ and $\mathrm{V}$ in 
the function are the 2-dimensional velocity vector. $\mathrm{X}$ and $\mathrm{Y}$ are the coordinates of the $\mathrm{U}$ and $\mathrm{V}$. startX and startY specifies the start point of the streamline. The function output is a vector of handle of each of the streamline.

\section{PROGRAMMING EXAMPLE}

Backward facing step flow is a classical CFD case, where the streamline has distinctive characteritics and the re-attachment length can be used to verify the CFD algorithm[3] accuracy. Therefore Backward facing step flow is selected as the example in this paper. The parameters used are listed below:

$\operatorname{Re}=133$, computation length $=7 \mathrm{~m}$; height $=2 \mathrm{~m}$; Mesh grid of 350 X 100; computation grid step $\Delta x=0.02 m, \Delta y=0.02 m$. CIMPLE algorithm is used on the G, Gx, Gy, Gxy grids for CFD computation.

The main programming of the streamline visualization is shown as follows:

clear all;

timeoutA=logintimeout(5);\% Set database time

conn = database('FLOWFIELD',",");

ping(conn);

cursorA=exec(conn,'SELECT * FROM Streamline_SQL');

setdbprefs ('DataReturnFormat','numeric'); Set return data type to numeric

cursorA=fetch(cursorA);

AA = cursorA.Data;

close(cursorA);

close(conn);

figure;

set(gcf,'position',[10,200,1000,400]);

set(gca,'position',[0.07,0.08,0.85,0.85]);

axis([0,7,0,2]);

box on;

$\mathrm{NX}=350$;

$N Y=100$;

$\mathrm{U}=$ zeros(NY,NX);

$\mathrm{V}=$ zeros(NY,NX);

for $\mathrm{l}=1$ :NX end

$$
\mathrm{a}(\mathrm{l})=\mathrm{l} \text {; }
$$

for $\mathrm{l}=1: \mathrm{NY}$

end

$$
\mathrm{b}(\mathrm{l})=\mathrm{l} \text {; }
$$

$[\mathrm{X}, \mathrm{Y}]=$ meshgrid(a,b);

$\mathrm{X}=\mathrm{X} * 0.02$;

$\mathrm{Y}=\mathrm{Y} * 0.02$;

[r,c]=size(AA);

for $\mathrm{l}=1: \mathrm{r}$

$\mathrm{J}=\mathrm{NY}-\mathrm{AA}(\mathrm{l}, 1)+1$;

$\mathrm{I}=\mathrm{AA}(1,2)$;

$\mathrm{u}=\mathrm{AA}(\mathrm{l}, 3)$;

$\mathrm{v}=-\mathrm{AA}(\mathrm{l}, 4)$;

$\mathrm{U}(\mathrm{J}, \mathrm{I})=\mathrm{u}$;

$\mathrm{V}(\mathrm{J}, \mathrm{I})=\mathrm{v}$;

end

for $\mathrm{l}=1: 2$ :NY

StartX(l)=1;

StartY $(\mathrm{l})=\mathrm{l}$;

end

Start $\mathrm{X}=$ Start $\mathrm{X} * 0.02$;

Start $Y=$ Start $Y * 0.02$;

$\mathrm{h}=$ streamline $(\mathrm{X}, \mathrm{Y}, \mathrm{U}, \mathrm{V}, \mathrm{Start} \mathrm{X}, \mathrm{Start} \mathrm{Y})$;

set(h,'color','black');

\%The following plots the lower left corner of the streamline diagram

StartX=[];

Start $\mathrm{Y}=[]$

StartX $=[75,75,75,75,75,75,75]$;

StartY $=[4,8,12,16,20,24,29]$;

Start $\mathrm{X}=$ Start $\mathrm{X} * 0.02$

Start $Y=$ Start $Y^{*} 0.02$;

$\mathrm{h}=$ streamline $(\mathrm{X}, \mathrm{Y}, \mathrm{U}, \mathrm{V}, \mathrm{Start} \mathrm{X}, \mathrm{Start} \mathrm{Y})$;

set(h,'color','black');

Figure 1 shows the area streamline plot as the programming output. The vector field is clear in the entire computation area, is satisfactory to most engineering project needs. The Figure 1 also shows an eddy, with a re-attachment length of $4 \mathrm{~m}$. This reflects the distinctive characteristics of the backward facing step flow, demonstrating the high accuracy of the CIMPLE algorithm used in this paper.

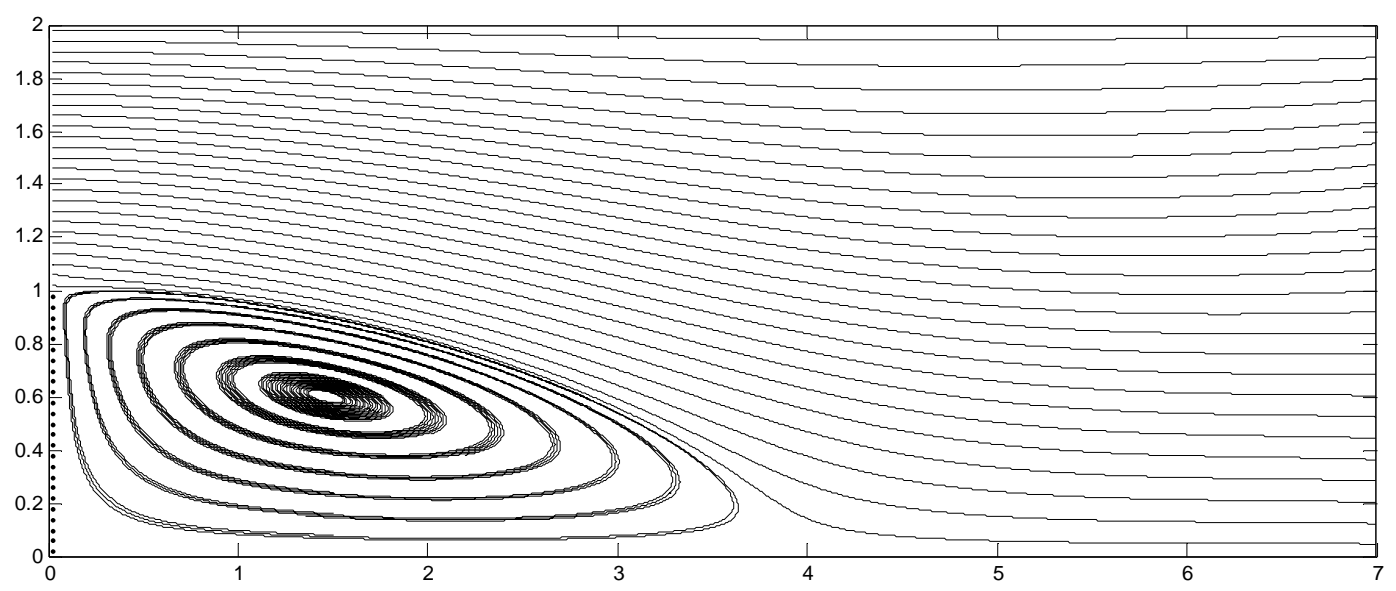

Fig.1 streamline plot of backward facing step flow 


\section{CONCLUSIONS}

(1) This paper demonstrates a streamline visualization programming method with database and MATLAB. It utilizes the CFD computation data stored in a database, and improves the data analyzing efficiency, which is important in visualizing and understanding high-performance CFD computation results in complex fluid dynamics cases.

(2) By separating the SQL commands for the data query and the plotting functions, this program has good portability with different database platforms.

\section{REFERENCES}

[1] Zhang Xiaojun, Tian Xia, Liu Zuyuan.Implement of MATLAB in Visualization of Numerical Data Produced by CFD[J].Journal of wuhan university of technology(transportation science\&engineering),2004,28(1), 126128.

[2] Xu Qin, Zheng Ningning, Huang Jingguo, Xu Ping. Retrieving Data from Earthquake Precursor Database Using MATLAB[J]. Technology for Earthquake Disaster Prevention, 2013, 8(2), 198-208.

[3] Yang Guanping, $\mathrm{Hu}$ Manyin, Gao Xianglin, Pan Chaohong, Tian Hezhong. Complete-implicit method for pressure-linked equations-CIMPLE Scheme[J]. Proceedings of the CSEE, 1999, 19(4), 4145. 